\title{
Rizobactérias no crescimento e na produtividade da cebola
}

\author{
Rhizobacteria on the production and yield of onion
}

\author{
Oscar Emilio Ludtke Harthmann' Átila Francisco Mógor' João Américo Wordell Filho ${ }^{\mathrm{III}}$ \\ Wilmar Cório da Luz
}

\begin{abstract}
- NOTA-
RESUMO

A associação de plantas com rizobactérias pode promover o crescimento vegetal, reduzindo custos de produção. As rizobactérias benéficas podem ser uma alternativa para a produção de cebola. Neste trabalho, foi avaliado o efeito da aplicação de rizobactérias no crescimento e na produtividade da cebola da cultivar 'Bola Precoce'. A aplicação foi realizada na Estação Experimental da Epagri, em Ituporanga, Santa Catarina (SC), no ano de 2008. O delineamento experimental foi em blocos ao acaso, com cinco repetições, sendo utilizadas as rizobactérias Pseudomonas spp. W6, Bacillus megaterium W19 e Bacillus cereus UFV40, microbiolizadas isoladamente

Bola Precoce onions. The study was conducted in the Experimental Station of Epagri, Ituporanga, SC, Brazil in 2008. The experimental design was in random blocks with five repetitions using Pseudomonas spp. W6, B Bacillus megaterium W19 e Bacillus cereus UFV40 rhizobacteria, microbiolized singly in seeds or in a formula together with non-treated control. The treatments involving rhizobacteria application yielded higher heights, diameter of pseudo-trunk and number of leaves in the plants assessed at 90 days after transplant. All the plants which received treatments with rhizobacteria presented better results considering the fresh weight and yield of bulb in relation to the control. The mass of bulbs were positively affected by the treatments, especially for Bacillus megaterium W19.
\end{abstract} nas sementes ou em mistura, juntamente com uma testemunha não tratada. Os tratamentos com aplicação de rizobactérias proporcionaram maior altura, diâmetro de pseudocaule e número de folhas nas plantas avaliadas aos 90 dias após o transplante. Plantas que receberam os tratamentos com rizobactérias apresentaram maior rendimento de bulbos em relação à testemunha. A massa dos bulbos foi afetada positivamente pelos tratamentos, com destaque para Bacillus megaterium W19.

Palavras-chave: Allium cepa, Bacillus megaterium, promoção de crescimento.

\section{ABSTRACT}

The association of plants with rhizobacteria can enhance plant growth, reducing production costs. Benefic rhizobacteria can stimulate plant growth being an alternative for production of onions. This research assesses the impact of applying rhizobacteria in the growth and productivity of $\mathrm{cv}$.
Key words: Allium cepa, Bacillus megaterium, promotion of growth.

A cebola, Allium cepa L., é uma das plantas cultivadas de mais ampla difusão no mundo. Originária da Ásia Central, foi introduzida no Brasil pelos portugueses no século XVI e atualmente é uma das hortaliças mais importantes, sendo cultivada na maioria das regiões brasileiras (BOITEUX \& MELO, 2004).

As rizobactérias benéficas são conhecidas na literatura como rizobactérias promotoras de crescimento vegetal - RPCV (LUZ, 1996), desempenhando funções importantes para a planta. Plantas microbiolizadas podem absorver mais

'Instituto Federal de Educação, Ciência e Tecnologia Catarinense. Estrada do Redentor, 5665, Bairro Canta Galo, CP 441, 89160000, Rio do Sul, SC, Brasil. E-mail: oscarelh@gmail.com. Autor para correspondência.

"Programa de Pós-graduação em Agronomia, Produção Vegetal, Universidade Federal do Paraná (UFPR), Curitiba, PR, Brasil.

IIIEmpresa de Pesquisa Agropecuária e Extensão Rural de Santa Catarina (EPAGRI-CEPAF), Chapecó, SC, Brasil.

${ }^{\mathrm{IV}}$ Revisão Anual de Patologia de Plantas (RAPP). Saul Irineu Farina, 111, Passo Fundo, RS, Brasil. 
rapidamente minerais da solução do solo e acumular mais massa seca. A associação de plantas com rizobactérias benéficas vem adquirindo importância crescente por ter efeitos na promoção de crescimento e no biocontrole de doenças radiculares e foliares, reduzindo custos de produção e diminuindo o impacto dos agrotóxicos no meio ambiente (ROMEIRO \& BATISTA, 2002). Em sistemas sustentáveis, o uso de rizobactérias promotoras de crescimento pode ser uma das alternativas tecnológicas viáveis para aumentar a produção, sendo implementada pela microbiolização de sementes com microrganismos. Nesse contexto, este trabalho teve como objetivo avaliar o efeito da microbiolização de cebola com rizobactérias no crescimento das plantas e na produção de bulbos.

A pesquisa foi realizada em campo, na Estação Experimental da Epagri, em Ituporanga, Santa Catarina (SC) (27 $25^{\prime}$ S, 49 $\left.38^{\circ} \mathrm{W}\right)$, com altitude de 475m e clima subtropical úmido (Cfa), segundo a classificação de Köeppen. O trabalho foi conduzido de abril a dezembro de 2008. Foram utilizadas sementes de cebola da cultivar 'Bola Precoce', a qual é indicada para cultivo em Santa Catarina.

O delineamento experimental utilizado foi o de blocos casualizados, com cinco tratamentos e cinco repetições. Os tratamentos constaram de testemunha sem microbiolização (T) e da aplicação nas sementes de Pseudomonas spp. (W6), Bacillus megaterium (W19), Bacillus cereus (UFV40) e mistura dos três isolados (Mistura). Para se realizar o preparo das suspensões rizobacteriana, cada isolado foi multiplicado separadamente em meio agar nutritivo (3g de extrato de carne em pó para microbiologia, $5 \mathrm{~g}$ de peptona de carne, 2,5g de glicose anidra, $15 \mathrm{~g}$ de agar e $1000 \mathrm{~mL}$ água destilada), em placas que foram incubadas a $23 \pm 2^{\circ} \mathrm{C}$, por 48 horas, conforme proposto por LUZ (2001). Após esse período, as células foram removidas da superfície do meio de cultura com um pincel e colocadas em água destilada esterilizada. A concentração das suspensões foi ajustada de acordo com a escala de McFarland (MCFARLAND, 1970) e o número de unidades formadoras de colônias de aproximadamente $10^{7} \mathrm{UFC} \mathrm{mL}^{-1}$. Em seguida, as sementes foram imersas nas suspensões bacterianas por cinco minutos, sendo agitadas, filtradas e deixadas para secar em temperatura ambiente, por 24 horas. As sementes da testemunha foram mantidas em água destilada esterilizada, agitadas por cinco minutos e deixadas secar sob temperatura ambiente, por 24 horas.

A semeadura foi feita a lanço, numa densidade de $2,5 \mathrm{~g} \mathrm{~m}^{-2}$. As plantas foram cultivadas conforme metodologia descrita nas recomendações da Epagri/Sistema de Produção para cebola (EPAGRI,
2000). Posteriormente, 90 dias após a semeadura, as mudas foram transplantadas para área de produção de bulbos, em linhas espaçadas de $0,4 \mathrm{~m}$, mantendo-se espaço de $0,1 \mathrm{~m}$ entre plantas no sulco preparado no sistema de cultivo mínimo. Cada parcela experimental foi constituída por oito linhas de plantio, com 4,0m de comprimento, perfazendo uma área de $12,8 \mathrm{~m}^{2}$, sendo 0,5m das extremidades, e as duas linhas externas consideradas como bordadura. A adubação em prétransplante foi baseada nas Recomendações de Adubação e de Calagem para os Estados do Rio Grande do Sul e Santa Catarina (COMISSÃO DE QUÍMICA E FERTILIDADE DO SOLO-RS/SC, 2004) e constou de $20 \mathrm{~kg} \mathrm{ha}^{-1}$ de nitrogênio, $80 \mathrm{~kg} \mathrm{ha}^{-1}$ de fósforo e $40 \mathrm{~kg} \mathrm{ha}^{-1}$ de potássio. A adubação de cobertura foi realizada 40 dias após transplante, quando foram aplicados $210 \mathrm{~kg}$ ha $^{-1}$ (26\% N; 5\% Ca, 2\% Mg, 9\% S e 0,3\% B).

Aos 90 dias após o transplante (DAT), foi realizada avaliação biométrica para medir a altura da planta, o diâmetro do pseudocaule $1 \mathrm{~cm}$ acima do solo e a contagem do número total de folhas por planta. $\mathrm{Na}$ colheita, foram efetuadas as avaliações de população e a produção total dos bulbos colhidos nas áreas úteis das parcelas. A colheita foi realizada aos 120DAT, quando $60 \%$ das plantas já tinham sofrido estalo. A cura foi realizada a campo, durante 14 dias. Após o período de cura, foi feita a limpeza dos bulbos colhidos por parcela, sendo cortadas as hastes e raízes. Foram avaliadas a produtividade total e a produtividade comercial de bulbos (bulbos perfeitos e com diâmetro transversal acima de $35 \mathrm{~mm}$ ), as quais são expressas em $\mathrm{kg} \mathrm{ha}^{-1}$. Calculou-se a massa média de bulbo comercial. Realizou-se a análise de variância, e as médias dos tratamentos foram comparadas pelo teste de Duncan, a $5 \%$ de probabilidade.

As aplicações de rizobactérias na cebola promoveram significativamente o crescimento da parte aérea das plantas avaliadas aos 90DAT, conforme resultados obtidos para o número de folhas, o diâmetro de pseudocaule e a altura de planta (Tabela 1). Para o número de folhas, o tratamento testemunha foi inferior e diferiu dos demais. O diâmetro de pseudocaule e a altura da parte aérea foram afetados pelos tratamentos, com exceção do tratamento W6, que não diferiu da testemunha. Todos os tratamentos foram superiores à testemunha em relação à produção total de bulbos, com destaque para os tratamentos W19, W6 e Mistura, que também apresentaram maior massa média de bulbo comercial (Tabela 1).

As diferenças em percentagem em relação à testemunha variaram de 15,7 a $24,4 \%$ para produção total de bulbos por hectare e de 4,3 a 13,5\% para massa média de bulbo comercial. As percentagens são 
Tabela 1 - Efeito da microbiolização de sementes de cebola da cultivar 'Bola Precoce' com rizobactérias avaliados aos 90 dias após o transplante das mudas sobre o número de folhas (NF), o diâmetro do pseudocaule (DP) e a altura da parte aérea (ALT) e sobre a população de plantas por hectare (PP), a produção de bulbos por hectare (PB) e a massa média de bulbo comercial (MMBC), avaliados aos 120 dias após o transplante. Ituporanga, SC, 2008.

\begin{tabular}{|c|c|c|c|c|c|c|c|}
\hline Variáveis & Testemu & nha & $\begin{array}{l}\text { W6 Pseudomonas } \\
\text { spp }\end{array}$ & $\begin{array}{c}\mathrm{W} 19 \\
\text { B.megaterium }\end{array}$ & UFV40 В. cereus & $\begin{array}{c}\text { W6+ W19+ } \\
\text { UFV40 }\end{array}$ & CV (\%) \\
\hline NF & 10,0 & $c^{1}$ & $10,4 \quad b$ & 11,0 a & $10,7 \mathrm{ab}$ & 10,9 & 2,40 \\
\hline DP Mm & 19,0 & $\mathrm{~b}$ & $19,8 \quad b$ & 21,1 a & 21,0 a & 21,1 & 3,54 \\
\hline ALT cm & 69,3 & c & 70,9 bc & 76,3 a & 77,2 & 74,1 & 4,07 \\
\hline PP n ha ${ }^{-1}$ & 254.157 & ns & 240.000 & 249.583 & 244.167 & 245.000 & 4,96 \\
\hline PB kg ha-1 & 34.850 & $\mathrm{~b}$ & $40.938 \quad$ a & $43.350 \quad \mathrm{a}$ & $40.334 \quad \mathrm{a}$ & $41.496 \quad$ a & 6,43 \\
\hline PB \% & 0 & & 17,5 & 24,4 & 15,7 & 19,1 & \\
\hline MMBC g & 158,0 & c & 173,4 ab & 179,4 a & 164,8 bc & $176,8 \quad a b$ & 5,35 \\
\hline MMBC \% & 0 & & 9,7 & 13,5 & 4,3 & 11,9 & \\
\hline
\end{tabular}

${ }^{\mathrm{ns}}$ Efeito de tratamento não significativo.

${ }^{1}$ Médias seguidas da mesma letra na linha não diferem significativamente entre si pelo teste de Duncan $(\mathrm{P}=0,05)$.

menores que as observadas por HARTHMANN (2009), que foram de $48 \%$, provavelmente pelo efeito das condições edafoclimáticas e pela adubação diferenciada no momento do transplante das mudas. As diferenças em percentagem dos tratamentos que diferiram significativamente da testemunha para a variável massa média de bulbo comercial (9,7 a 13,5\%) são semelhantes às obtidas por BALEMI et al. (2007), que observaram aumento de $13,5 \%$ na produção de bulbos comercializáveis com a microbiolização com rizobactérias. Esses resultados confirmam as conclusões de KARTHIKEYAN et al. (2008) de que a cebola responde à microbiolização de rizobactérias nas sementes.

A capacidade de estimular o crescimento vegetal apresentada pelas rizobactérias tem sido atribuída a vários mecanismos, dentre eles, a produção de hormônios, e como consequência o aumento no crescimento das raízes e na parte aérea, no número de folhas, na área foliar e no rendimento de culturas. Caso pelo menos uma dessas modificações for observada, ela pode ser considerada como promotora de crescimento vegetal (PATTEN \& GLICK, 1996). O aumento no volume de raízes de plantas devido ao efeito da microbiolização de rizobactérias nas sementes de cebola provavelmente permitiu maior absorção de água e nutrientes pela planta e, como consequência, incremento na produção de bulbos (HARTHMANN, 2009).

Os isolados Pseudomonas W6, $\boldsymbol{B}$. megaterium W19 e B. cereus UFV40 promoveram o crescimento das plantas após o transplante das mudas na fase de crescimento vegetativo e de produção de bulbos (Tabela 1). Esses resultados concordam com os obtidos por KARTHIKEYAN et al. (2008), os quais, estudando o efeito de $\boldsymbol{P}$. fluorescens, B. subtilis e $\boldsymbol{T}$. viride no controle de Alternaria palandui, obtiveram incremento em crescimento vegetal e produção de bulbos em casa de vegetação e em condições de campo, assim como NEVES (2001), que relatou diferenças significativas entre isolados para as variáveis altura de plantas, massa fresca e seca de bulbos e massa seca de raiz.

A aplicação de rizobactérias nas sementes de cebola da cultivar 'Bola Precoce' promove o crescimento e o rendimento de bulbos, com destaque para B. megaterium W19.

\section{REFERÊNCIAS}

BALEMI, T. et al. Response of onion (Allium cepa L.) to combined application of biological and chemical nitrogenous fertilizers. Acta Agriculturae Slovenica, v.89, n.1, p.107114, 2007.

BOITEUX, L.S.; MELO, P.C.T.de. Taxonomia e origem. In: EMBRAPA HORTALIÇAS. Sistema de produção de cebola (Allium cepa L.). Brasília: Embrapa-CNPH. Sistemas de Produção, 5, ISSN 1678-____ Versão Eletrônica, 2004. Disponível em: <http://www.cnph.embrapa.br/sistprod/cebola/ index.htm>. Acesso em: 07 out. 2006.

COMISSÃO DE QUÍMICA E FERTILIDADE DO SOLO - RS/ SC. Manual de adubação e calagem para os Estados do Rio Grande do Sul e Santa Catarina. 10.ed. Porto Alegre, 2004. 394p.

EPAGRI. Sistema de produção para cebola: Santa Catarina. 3.rev. Florianópolis, 2000. 91p. (Epagri. Sistemas de Produção, 16).

HARTHMANN, O.E.L. Efeito da microbiolização de sementes com rizobactérias na produção de cebola. 2009. 115f. Tese (Doutorado em Ciências Agrárias) - Pós-graduação em Agronomia, Setor de Ciências Agrárias, Universidade Federal do Paraná, Curitiba, PR.

Ciência Rural, v.40, n.2, fev, 2010. 
KARTHIKEYAN, M. et al. Biological control of onion leaf blight disease by bulb and foliar application of powder formulation on antagonist mixture. Archives of Phytopathology and Plant Protection, v.41, n.6, p.407417, 2008.

LUZ, W.C. Evaluation of plant growth-promoting and bioprotecting rhizobacteria on wheat crop. Fitopatologia Brasileira, v.26, p.597-600, 2001.

LUZ, W.C. Rizobactérias promotoras de crescimento de plantas e de bioproteção. In: LUZ, W.C. et al (Ed.). Revisão anual de patologia de plantas (RAPP). Passo Fundo: Padre Berthier dos Missionários da Sagrada Família, 1996. V.4, p.1-49.

MCFARLAND, J. The nephelometer: Na instrument for estimating the number of bacteria in suspensions used for calculating the opsonic index and for vaccines. In: CAMPBELL,
H.D. et al. (Eds.). Methods in immunology. New York: Benjamin, 1970. p.435-437.

NEVES, D.M.S. Controle biológico de Pseudomonas marginalis Pv. Marginalis e promoção de crescimento de cebola pela microbiolização de sementes. 2001. $47 \mathrm{f}$. Dissertação (Mestrado em Fitopatologia) - Universidade Federal de Pelotas, Faculdade de Agronomia Eliseu Maciel, Pelotas, RS.

PATTEN, C.; GLICK, B.R. Bacterial biosynthesis of indole-3acetic acid. Canadian Journal Microbiology, v.42, p.207220, 1996

ROMEIRO, R.S.; BATISTA, U.G. Preliminary results on PGPR research at the Universidade Federal de Viçosa, Brasil, 2002. Disponível em: <http\\:www.ufv.br/dfp/bac/ Cordoba.html>. Acesso em: 05 dez. 2006. 